\title{
Release of single cells from the colonial oil-producing alga Botryococcus braunii by chemical treatments
}

\author{
Liyuan Hou • Hyunsun Park • Shigeru Okada • \\ Takeshi Ohama
}

Received: 4 June 2013 / Accepted: 30 July 2013 / Published online: 13 August 2013

(C) The Author(s) 2013. This article is published with open access at Springerlink.com

\begin{abstract}
We tested for chemical reagents that would be useful in preparing a large number of vital single cells from colonial Botryococcus braunii B-race, variety Showa. Among the 18 reagents assayed, glycerol and erythritol showed the highest potency for releasing single cells. Incubation in medium containing these reagents released $40-50 \%$ single cells in $15 \mathrm{~min}$. Fluorescent staining with Nile red revealed that except for the cap-like structures the released single cells were free of hydrocarbon oils that accumulated in the extracellular matrix where the single cells were embedded. However, to maintain the prepared single cells in vital condition, they must be maintained at a high concentration $\left(>2 \times 10^{7}\right.$ cells $\left./ \mathrm{ml}\right)$; at low concentrations, they rapidly lost chlorophyll and get disrupted. In contrast to the above results obtained using Brace, Showa, single cells prepared from A-race varieties survived even at low cell concentrations.
\end{abstract}

Keywords Botryococcene $\cdot$ Single cell isolation $\cdot$ Shell structure $\cdot$ Extracellular matrix $\cdot$ Hydraulic force

Handling Editor: Peter Nick

Electronic supplementary material The online version of this article (doi:10.1007/s00709-013-0537-4) contains supplementary material, which is available to authorized users.

L. Hou $\cdot$ H. Park $\cdot$ T. Ohama $(\bowtie)$

School of Environmental Science and Engineering, Kochi University of Technology (KUT), Tosayamada, Kochi 782-8502, Japan e-mail: ohama.takeshi@kochi-tech.ac.jp

H. Park $\cdot$ S. Okada $\cdot$ T. Ohama

JST, CREST, 5 Sanbancho, Chiyoda, Tokyo 102-0075, Japan

S. Okada

Laboratory of Aquatic Natural Products Chemistry, Graduate School of Agricultural and Life Sciences, University of Tokyo, 1-1-1 Yayoi, Bunkyo-ku, Tokyo 113-8657, Japan

\section{Introduction}

Over the past two decades, interest in finding new sources of renewable energy has stimulated efforts to identify microalgae capable of generating large amounts of biofuel. The hydrocarbon oils of Botryococcus braunii (Chlorophyta, Trebouxiophyceae) are one of the most useful renewable sources of fossil fuel substitutes (Komárek and Marvan 1992; Sawayama et al. 1995; Banerjee et al. 2002; Kita et al. 2010). This cosmopolitan freshwater to brackish-water green alga is classified into three biochemical races: A, B, and L, according to the types of primal hydrocarbon oils they produce (Metzger and Casadevall 1991).

To accomplish the mass production of hydrocarbons at a reasonable price, application of molecular biological techniques for $B$. braunii are essential. However, accumulated hydrocarbon oils in the extracellular matrix hamper the biolistic transformation and selection of drug-resistant mutants. DNA fragments, which are noncovalently attached on the surface of biolistic bombardment particles, may get detached in the secreted oils before their delivery into the cell. Extracellular oils also prevent the access of enzymes added for cell wall digestion to prepare protoplasts for cell fusion. Single cells that are free of the oils would be extremely useful for genetic manipulation of this alga.

Before this study, successful isolation of single cells of $B$. braunii had been reported by the addition of glycerol (chemical race not mentioned) as a short proceeding of an annual meeting in Japan (Ikehara et al. 2011). However, the detailed methodology and the characteristics of the prepared cells were not described. With this background, we searched for reagents useful in the efficient release of single cells from B. braunii colonies, and analyzed the physical characteristics of the isolated single cells. This study was mainly performed using a B-race variety known as Showa. For comparative study, we used another B-race variety, Sanshiro-5, and two A-race varieties, UTEX 572 and Yamanaka (Okada et al. 1995). 


\section{Materials and methods}

\section{Strains and culture of B. braunii}

Two A-race varieties, UTEX 572 (The Culture Collection of Algae, University of Texas at Austin) and Yamanaka (Okada et al. 1995), and two B-race varieties, Showa (University of California Berkeley Herbarium, accession no. UC 147504) (Nonomura 1988) and Sanshiro-5 (Okada et al. 1995), were used for comparative study. "modified Chu 13 medium" (Grung et al. 1989) was used to culture the two B-race varieties and the Yamanaka variety of A-race. The A-race variety UTEX 572 was cultured in "modified Chu 10 medium" (Bold and Wynne 1978). Conical Fernbach flasks capped with Styrofoam stoppers were used for liquid culture. They were maintained in an acrylic resin chamber filled with an approximately $0.8 \%$ air- $\mathrm{CO}_{2}$ mixture at $25{ }^{\circ} \mathrm{C}$ under continuous white fluorescent illumination $\left(50 \mu \mathrm{mol}\right.$ photons $\left.\mathrm{m}^{-2} \mathrm{~s}^{-1}\right)$ without shaking.

Chemical reagents tested for the preparation of single cells

In total, we tested 18 reagents for their potency in releasing single cells: acetone (012-00343; Wako, Osaka, Japan), 2,3butanediol (022-03242; Wako), diglycerol (627-82-7; TCI, Tokyo, Japan), dimethyl sulfoxide (043-07216; Wako), erythritol (056-00242; Wako), ethylene glycol (058-03965; Wako), glucose (041-00595; Wako), glycerol (072-00621; Wako), glycerol ethoxylate-co-propoxylate triol (51258-152; Sigma-Aldrich Japan, Tokyo, Japan), glyceryl guaiacolate (93-14-1; Alfa Aesar, London, UK), mannitol (130-00855; Wako), n-hexane (085-00416; Wako), pentaerythritol (16900585; Wako), sorbitol (098-03755; Wako), sucrose (19600015; Wako), triglycerol (20411-31-8; Aldrich), Tween 20 (103168; ICN, California, USA), and xylitol (87-99-0; SigmaAldrich Japan). Each reagent, except acetone, mannitol, nhexane, pentaerythritol, glyceryl guaiacolate, and Tween 20, was dissolved in modified Chu 13 medium to obtain a final concentration of $3.43 \mathrm{M}$; this is approximately equivalent to the concentration of $25 \%(\mathrm{v} / \mathrm{v})$ glycerol. Tween 20 was dissolved in modified Chu 13 medium at a concentration of $25 \%(\mathrm{v} / \mathrm{v})$. Saturated solutions of mannitol, pentaerythritol, and glyceryl guaiacolate were prepared because the solubility of these compounds is lower than $3.43 \mathrm{M}$. Absolute acetone and $n$-hexane were also used for single cell isolation.

Release of single cells

Experimental phase colonies were collected from $40 \mathrm{ml}$ of culture by filtration using a $5-\mu \mathrm{m}$ nylon mesh. Colonies on the mesh were suspended in $10 \mathrm{ml}$ of the appropriate medium (i.e., Chu 13 or Chu 10 containing a specific reagent). Microscopic observation was conducted to estimate the ratio of single cells released from the colonies.
After treatment with a specific chemical reagent, released single cells and colonies were separated using a 5- $\mu \mathrm{m}$ nylon mesh: single cells passed through this mesh, while colonies were trapped. Single cells in the filtrate were precipitated by centrifugation $(1,000 \times g$ for $5 \mathrm{~min})$, and the cell pellet was suspended in $10 \mathrm{ml}$ of Chu 13 (or Chu 10) and re-centrifuged to remove residual chemical reagents. Finally, precipitated single cells were suspended in an appropriate volume of medium to test their viability.

For small-scale preparation of single cells, released single cells were filtered through a $0.45-\mu \mathrm{m}$ pore membrane filter, single cells in the membrane were washed three times with $10 \mathrm{ml}$ of modified Chu 13 (or Chu 10) medium, and suspended in an appropriate volume of medium.

Measurement of ratio of chlorophyll-containing single cells to those without chlorophyll

We prepared single cells from experimental phase colonies using a $3.43 \mathrm{M}$ glycerol treatment for $15 \mathrm{~min}$, and analyzed the effect of cell concentration on vitality through measuring the ratio of chlorophyll-containing single cells on day 6 after establishing single-cell culture. Through microscopic observation, we distinguished the chlorophyll-containing cells from those without chlorophyll, and counted both types of cells using a hemacytometer. Moreover, the relationship between the ratio of single cells released and the concentration of chemical reagents was analyzed for glycerol, erythritol, glyceryl guaiacolate, xylitol, sorbitol, glucose, mannitol, and sucrose by incubating the isolated single cells in medium containing various concentrations $(0.86,1.72$, and $3.4 \mathrm{M})$ of these reagents.

\section{Preparation of crude hydrocarbons}

Colonies of Showa (B-race) were harvested from 3-1 cultures

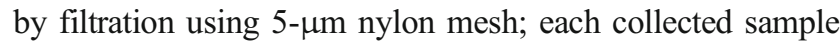
was then freeze-dried and weighed. Freeze-dried algal cells were extracted with acetone by sonication, and these were centrifuged at $1,000 \times g$ at room temperature for $5 \mathrm{~min}$. We followed the methods described by Okada et al. $(1997,1998)$ and Tonegawa et al. (1998) to extract and purify the hydrocarbon oils.

Fluorescence observations

We stained hydrocarbons by adding $10 \mu \mathrm{l}$ of Nile red (SigmaAldrich Japan) stock solution $(500 \mu \mathrm{g} / \mathrm{ml}$ in ethanol) to $1 \mathrm{ml}$ of the sample. We observed fluorescence within 30 min using an Olympus IX70 microscope equipped with an Olympus UMWU2 filter unit.

To visualize cell walls, we added $10 \mu \mathrm{l}$ of Fluorescent Brightener 28 (Sigma-Aldrich Japan) (1 mg/ml in water) to 
$1 \mathrm{ml}$ of isolated single cell suspension. We observed fluorescence after $15 \mathrm{~min}$ using an Olympus IX70 microscope equipped with a U-MWU2 filter unit.

\section{Results}

Effective chemical reagents for single cell release

The potency of each reagent for releasing single cells was evaluated by microscopic observation at $15 \mathrm{~min}$ after chemical treatment. Colonies prepared from exponential phase culture consistently produced about $30 \%$ more single cells than those from stationary phase culture across all potent reagents, irrespective of differences between races or varieties. Release of single cells began at the edges of the colonies (Fig. 1; Online Resources 1 and 2), and the release of single cells slowed gradually to a halt after $30 \mathrm{~min}$ in the potent reagents. Results of the chemical treatments are summarized in Table 1 . In Showa (B-race) and Sanshiro-5 (B-race), glycerol and erythritol showed the highest potency among the 18 reagents tested. These two reagents released as much as $30-50 \%$ of the cells in Showa and Sanshiro-5 colonies within $15 \mathrm{~min}$, while it was limited to $10-20 \%$ in Yamanaka (A-race). Glyceryl guaiacolate was also very efficient reagent in the preparation of single cells for Showa (B-race) and Sanshiro-5 (B-race), whereas it was not effective for Yamanaka (A-race). Unfortunately, this reagent was apparently harmful because colonies suspended in the medium changed color from green to brown in $1 \mathrm{~h}$. The ratio of single cells reached $20-30 \%$ in treatments using sorbitol or xylitol for Showa (B-race) (Table 1). Glucose and mannitol treatments produced 10-20\% Showa single cells (B-race), while these reagents released almost no single cells in Sansiro-5 (B-race) and Yamanaka (A-race). Treatment with sucrose generated very few Showa single cells, while it released no single cells in Sanshiro-5 (B-race) and Yamanaka (A-race).

Because acetone is an efficient solvent for extracting botryococcene (Okada et al. 1997, 1998; Tonegawa et al. 1998), we tested its potency for releasing single cells. Acetone showed high potency for releasing single cells from
Showa (B-race), Sanshiro-5 (B-race), and Yamanaka (A-race), but not from UTEX 572 (A-race). The single cell ratio reached $20-40 \%$ with absolute acetone treatment. However, acetone treatment disrupted almost all single cells released within $15 \mathrm{~min}$, regardless of the race. Therefore, irrespective of their high potency for releasing single cells, glyceryl guaiacolate and acetone are not optimal reagents for preparing vital single cells. $n$-Hexane, another solvent tested, released only $2-3 \%$ single cells from Showa (Table 1), but the single cells were not disrupted immediately.

For reagents identified as potent, we confirmed that there was a clear positive relationship between the reagent concentration and ratio of single cells released using Showa (Table 2). Whereas the single cell release ratio significantly decreased when the reagent concentration reduced to one half of the tested concentration, almost all reagents lost single cell release potential when one fourth of the test concentration was applied.

Characteristics of the reagents that showed potential to release single cells

In this study, we tested reagents for potency in the preparation of large quantities of single cells from colonial B. braunii, considering that glycerol had already been reported to be a potent reagent (Ikehara et al. 2011). Glycerol is a polyalcohol; we therefore tested hydroxyl group $(-\mathrm{OH})$-containing reagents (the number of $-\mathrm{OH}$ groups are shown in brackets below): ethylene glycol (2), 2,3-butanediol (2), glyceryl guaiacolate (2), diglycerol (4), meso-erythritol (4), pentaerythritol (4), xylitol (5), and triglycerol (5) (see Online Resource 3 for structural formulae). We also tested glycerol ethoxylate-co-propoxylate triol because of its molecular configuration. Furthermore, we tested glucose, mannitol, sorbitol, and sucrose because in the process of reagent selection, xylitol was found to be a potent single-cell-inducing reagent. Two weak detergents, Tween 20 and dimethyl sulfoxide were also tested. For reagents with sufficient solubility, we prepared a $3.43 \mathrm{M}$ solution of each reagent (corresponding to a $25 \% \mathrm{v} / \mathrm{v}$ concentration of glycerol) by dissolving them in Chu 13 medium. When the solubility of the reagent was below $3.43 \mathrm{M}$, we prepared a saturated

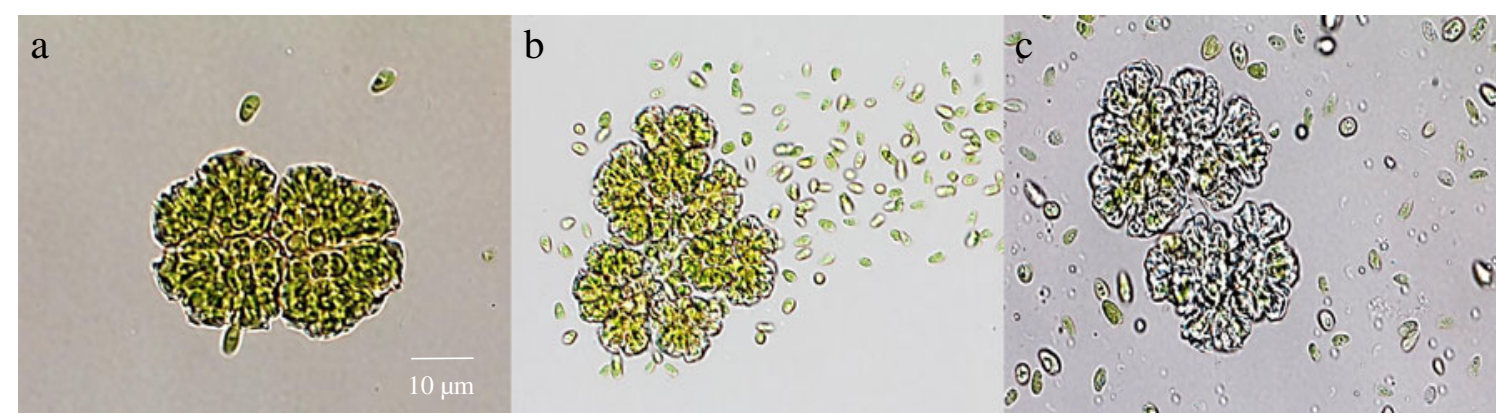

Fig. 1 Process of single cell release following glycerol treatment. a One minute after the addition of $3.43 \mathrm{M}$ glycerol to a colony of $B$. braunii in an exponentially growing culture. $\mathbf{b}$ Ten minutes after the addition of glycerol. $\mathbf{c}$ Fifty minutes after the addition of glycerol 


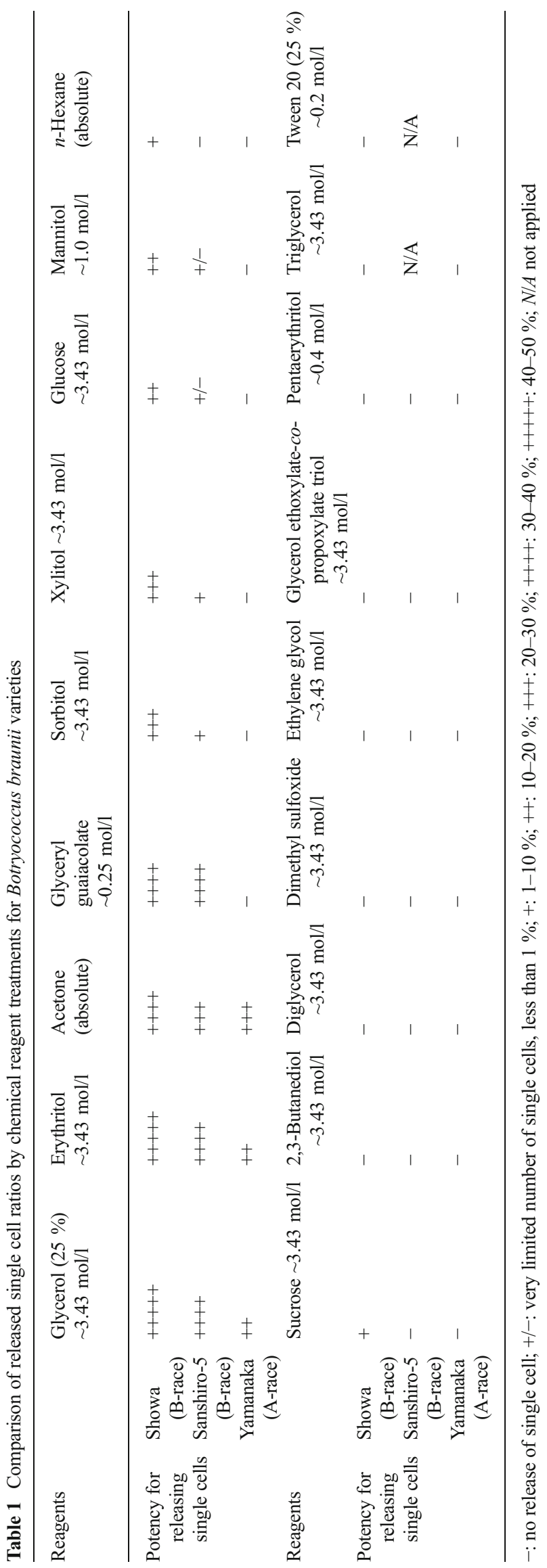

solution. Because acetone and $n$-hexane are often used as solvents to extract botryococcene, these reagents were also tested.

As many as ten reagents showed potency (Table 1, Online Resource 3) for releasing Showa single cells (B-race). However, the ten potent reagents did not share any apparent chemical similarities.

Characteristics of released single cells

Through Fluorescent Brightener 28 staining, we confirmed the presence of a cell wall around single cells (data from Showa is shown in Fig. 2a and b). Except for the cap-like structures on the broad ends of single cells (see below), no Nile red fluorescence was observed around the cell wall of these single cells (Fig. 2c). Moreover, even after treatment with glycerol, the hydrocarbon content of the matrix was not apparently reduced (Online Resource 4). This suggests that glycerol is not an efficient solvent for the hydrocarbon oils located in the B-race matrix.

Immediate observation of the chemically released Showa single cells showed that they possessed cap-like structures on their broad ends (Fig. 2c). The cap-like structures were highly morphologically similar to the previously reported "shell" structure (Weiss et al. 2012) that was abundantly accumulated in the old culture medium of Showa. Therefore, the shell structure was assumed to be the excised segment of the retaining wall and its fibril sheath, which is the outermost barrier that prevents the dispersion of the secreted oils from the matrix.

Our histochemical tests of the shells collected from the old Showa culture medium revealed that they were not stained by Nile red or Brightener 28 (Online Resource 5), as reported by Weiss et al. (2012). However, the cap-like structures appeared by glycerol treatment were strongly stained by Nile red but not Brightener 28 (Fig. 2b and c). This result was also observed for another B-race variety, Sanshiro-5. With the exception of the difference in Nile red staining, the shape of the cap-like structure located at the top of the released single cell was exactly the same as that of the "shell" accumulated in the culture medium (Online Resource 5A).

In contrast to the aforementioned observation, in the case of Yamanaka (A-race), the cap-like structures appeared to precede the release of single cells by glycerol treatment from the surface of the retaining wall. Subsequently, the cap-like structures and the single cells were separately slowly released into the medium. We collected the shell-like structures from the old culture medium of Yamanaka and B-race varieties. They were not stained by Nile red or Brightener 28, similar to Showa and Sanshiro-5.

In stark contrast to the above three cases, no single cells or shell-like structures of UTEX572 were released at all by chemical treatments; therefore, we could not obtain any shell- 
Table 2 Relationship between the concentration of reagents and the single cell releasing potency

\begin{tabular}{|c|c|c|c|c|c|c|c|c|}
\hline Concentration of reagent & Glycerol & Erythritol & Glyceryl guaiacolate & Xylitol & Sorbitol & Glucose & Mannitol & Sucrose \\
\hline $0.86 \mathrm{M}$ & + & - & $*$ & - & - & - & $\_\S$ & - \\
\hline $1.72 \mathrm{M}$ & +++ & ++ & $+^{* *}$ & ++ & + & + & $\_\S \S$ & - \\
\hline $3.43 \mathrm{M}$ & +++++ & +++++ & $++++^{* * *}$ & +++ & +++ & ++ & $++^{\S \S \S}$ & + \\
\hline
\end{tabular}

-: no release of single cell; +: 0-10\%; ++: 10-20\%; +++: 20-30\%; ++++: 30-40\%; +++++: 40-50\%;

${ }^{*} 0.0625 \mathrm{M},{ }^{* *} 0.125 \mathrm{M},{ }^{* * *} 0.25 \mathrm{M}$ (see text); ${ }^{\S} 0.25 \mathrm{M},{ }^{\S \S} 0.5 \mathrm{M},{ }^{\S \S} 1.0 \mathrm{M}$ (see text)

like structures by centrifugation of the old culture medium of UTEX572.

\section{Viability of prepared single cells}

We first tested the growth of Showa single cells (B-race) on a PFE membrane filter placed on a $0.8 \%$ agar Chu 13 medium plate. Unexpectedly, greenish single cells on the membrane changed to white in 2 days, and after 2 months no single cell had formed a colony. However, colonial cells grew well on the filter (data not shown). Considering the above results, we undertook detailed experiments to discover conditions suited for the survival of Showa single cells.

We analyzed the effect of cell concentration on the vitality of single cells. Showa single cells (B-race) prepared using the glycerol treatment were incubated at several different concentrations: approximately $0.6 \times 10^{6}, 1.5 \times 10^{6}, 3 \times 10^{6}$, and $2 \times 10^{7}$ cells $/ \mathrm{ml}$ in Chu 13 medium and kept under continuous light without shaking. We counted the number of chlorophyllcontaining single cells on day 6 . Table 3 shows that when they were maintained at a concentration higher than $2 \times 10^{7}$ cells $/ \mathrm{ml}$ in Chu 13 without any additions, approximately $70 \%$ Showa single cells contained chlorophyll on day 6 . In contrast, when maintained at a concentration lower than approximately $2 \times 10^{6}$ cells $/ \mathrm{ml}$, almost all single cells were disrupted or lost their chlorophyll by day 6 (Table 3 ). Thus, a high cell concentration seems to have a critical effect on the viability of single cells: Showa single cells (B-race) maintained at high concentration $\left(>2 \times 10^{7}\right.$ cells $\left./ \mathrm{ml}\right)$ were gathered together to form aggregates (Fig. 3a), while the size of the aggregates were much smaller and looser for those kept at low concentration $\left(0.5-3.8 \times 10^{6}\right.$ cells $\left./ \mathrm{ml}\right)$ (Fig. 3b). The same phenomenon was observed for Sahshiro-5 (B-race) (data not shown).

Moreover, we tested the effect of various additives to $\mathrm{Chu}$ 13 medium on Showa single cells. Considering that osmotic pressure might be one of the factors affecting the survival rate of single cells ( $0.6 \mathrm{M}$ mannitol is isotonic to the cytoplasm; Okada et al., unpublished data), various concentrations of glycerol, xylitol, sorbitol, and sodium chloride $(\mathrm{NaCl})$, which are typically used in osmotic pressure adjustment, were selected for this study.

Addition of sorbitol or xylitol to low concentrations of cells $\left(0.5-3.8 \times 10^{6}\right.$ cells $\left./ \mathrm{ml}\right)$ distinctly improved the ratio of chlorophyll-containing cells, to a maximum of $30 \%$ (Table 3), whereas the effect was more limited when the reagents were added to highly concentrated cell cultures. Addition of sorbitol enhanced cell aggregation, notably for low-concentration cell cultures, while the effect of xylitol was much weaker (data not shown). In contrast, xylitol and $\mathrm{NaCl}$ did not show such an effect nor induce aggregation of single cells grown at low cell concentration. The potential to induce aggregation seems to be related to the potential to increase viability of single cells.

In contrast to the results obtained for B-race varieties, Yamanaka (A-race) single cells prepared by glycerol treatment showed a high survival ratio. More than $60 \%$ of single cells contained chlorophyll on day 6 , regardless of whether they were maintained at high or low cell concentration (approximately $1 \times 10^{6}$ cells $/ \mathrm{ml}$ ) in Chu 13 medium without any additions.

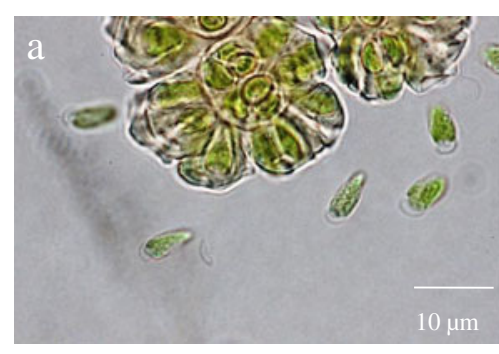

Fig. 2 Characteristics of Showa single cells released by glycerol treatment. a Normal view of Showa single cells. b Showa single cells stained with Fluorescent Brightener 28. The same targets

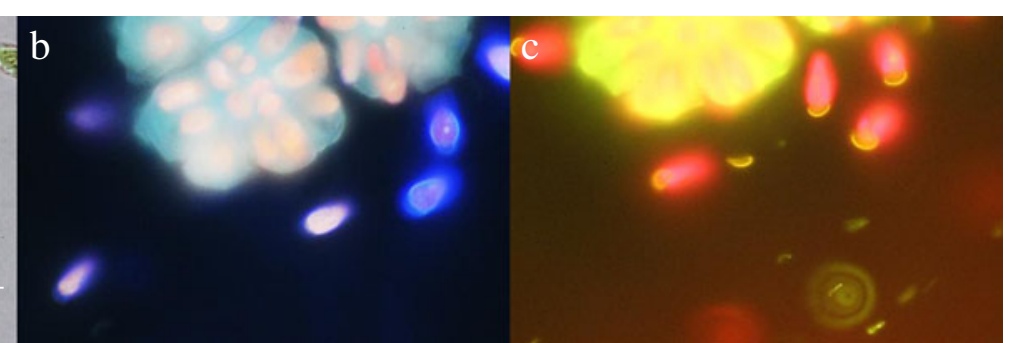

shown in a were observed by switching the filter set. c Showa single cells stained by Nile red. The same targets shown in a were observed by switching the filter set 


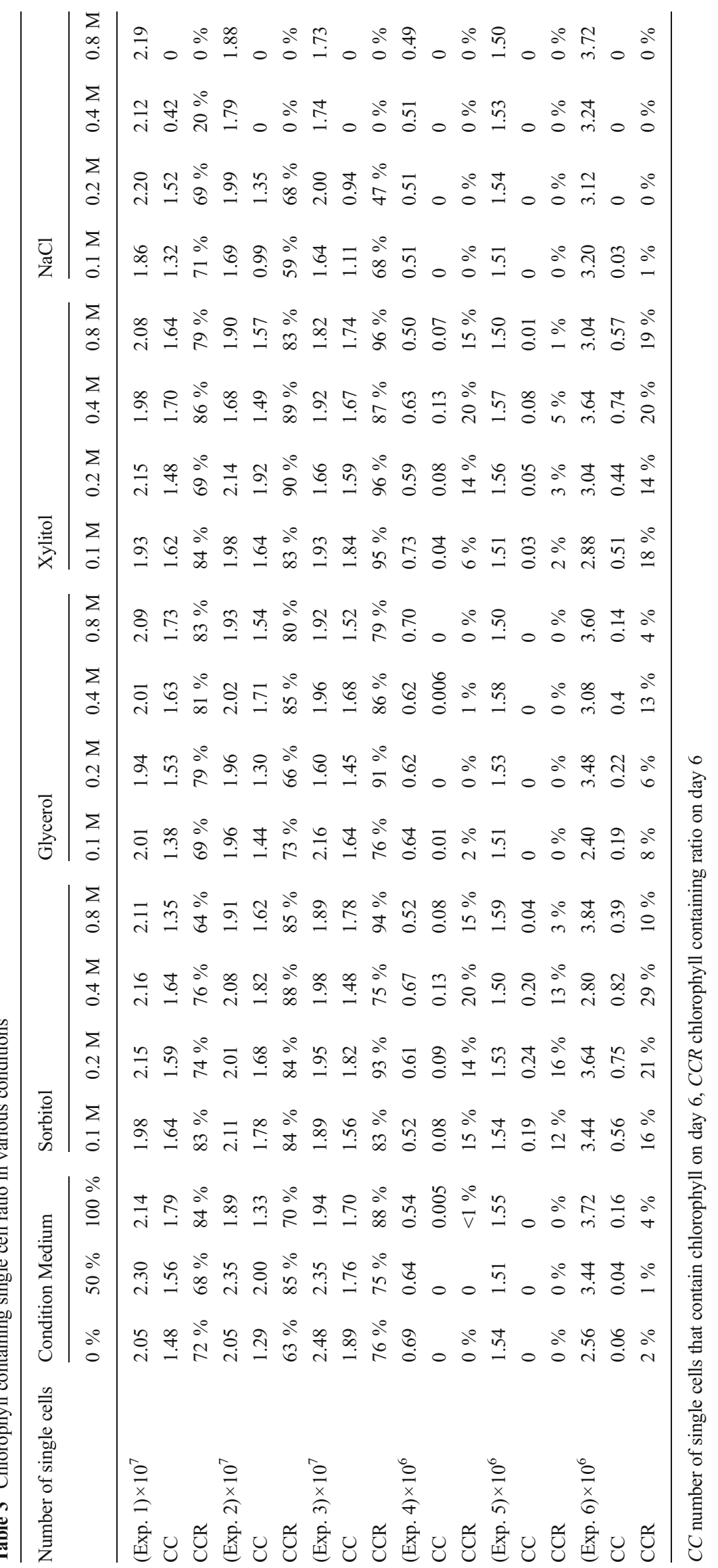




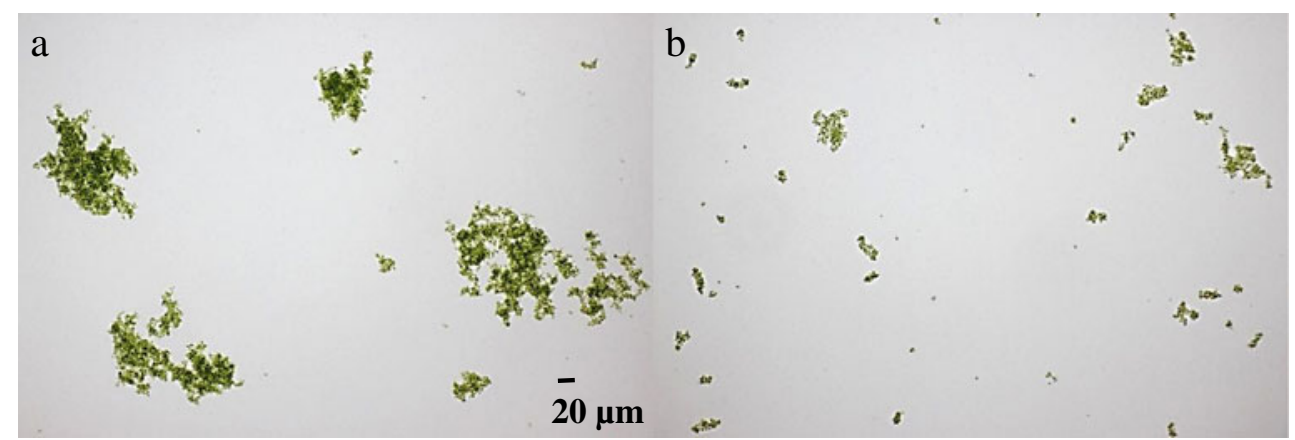

Fig. 3 Aggregates of single cells. a Aggregates of Showa single cells in Chu 13 medium at high cell concentration. Day 3 image of aggregates after the start of incubation of single cells. b Aggregates of Showa single cells in Chu 13 medium at low cell concentration. Day 3 image of aggregates after the start of incubation of single cells
The survival of single cells was also observed for the other A-race variety, UTEX572. None of the reagents tested were useful for releasing single cells of UTEX 572. However, single cells were easily generated by vortexing with glass beads ( $0.5 \mathrm{~mm}$ diameter). Such mechanically generated single cells of UTEX 572, maintained at low concentration (approximately $1 \times 10^{6}$ cells $/ \mathrm{ml}$ ), also showed a high survival ratio, similar to that observed in chemically isolated Yamanaka (Arace) single cells. Such mechanically prepared single cells were used to evaluate the harmful effect of glycerol treatment as described below.

We treated the mechanically prepared UTEX 572 single cells with $3.43 \mathrm{M}$ glycerol for $30 \mathrm{~min}$ to evaluate the influence of the chemical treatment. Even with such chemical treatment, the survival ratio of the UTEX 572 single cells on day 6 was not apparently different from the non-treated ones (data not shown). This shows that the rapid loss of chlorophyll observed in B-race single cells, which had been released by glycerol treatment, is not due to the harmful effects of the reagent.

\section{Discussion}

The main hydrocarbons produced by A-race B. braunii are alkadienes and alkatrienes (Templier et al. 1984, 1991; Metzger et al. 1985a, 1986), while that of B-race B. braunii is a triterpene known as botryococcene (Metzger et al. 1985b, 1987, 1988). Nile red is an extremely useful fluorescent lipophilic dye for staining botryococcene, alkadienes, alkatrienes, and other lipids (Weiss et al. 2010a).

Showa and Sanshiro-5, which are varieties of the B-race, secrete large amounts of botryococcene (Online Resource 6A, B) and their single colonies are embedded in an extracellular matrix composed of polymerized and liquid hydrocarbons (Blackburn 1936). Yamanaka (A-race) also secretes a substantial amount of oils into the colony matrix (Online Resource 6C). However, UTEX 572 cells (A-race) secrete no or at most very limited amounts of oils (Online Resource 6D). Cultures of UTEX 572 (A-race) and Yamanaka (A-race) contain a low ratio of naturally generated single cells, while no such single cells were observed in Showa (B-race) and Sanshiro-5 (Brace). This implies A-race single cells inherently have the ability to survive without forming colonies.

Because it is known that glycerol is a potent releaser of single cells (Ikehara et al. 2011), we assessed 18 reagents, including glycerol, in this study. Among those tested, ten reagents (including acetone and $n$-hexane) demonstrated the potential to release Showa single cells (Table 1). However, we were unable to identify any common chemical characteristics that were shared by these potent reagents. Most of the potent reagents useful for Showa were also useful for Yamanaka, which produced alkadienes, but not botryococcene, as the major hydrocarbon products. Thus, these findings suggest that single cell release was probably not due to organic chemical reactions between the added reagents and the hydrocarbon oils.

Microscopic observation of the single cell release process suggested that they were mechanically forced out of the extracellular matrix (Online Resource 1). The mode of action of release was apparently the same, regardless of differences in reagents and varieties. We suspect that the mechanical force may be a hydraulic pressure that was generated by the increased volume of the extracellular matrix, which was caused by the dissolution of chemical reagents into the matrix hydrocarbons. It is possible that the volume of the extracellular matrix was increased due to the resolved chemical reagents in the matrix hydrocarbon oils. We hypothesize that the hydraulic force caused by the aforementioned mechanism must push the extracellular matrix hydrocarbon oils into the retaining wall and also the embedded cells to outside of the matrix, thereby leading to the breakdown of the retaining wall. This model is illustrated in Fig. 4.

It is likely that the naturally accumulated shells in the old culture medium are generated via the enlargement of colonies and their separation into subcolonies. In such cases, the fragmentation of the retaining wall probably occurs very slowly and without the accompanying strong hydraulic pressure that pushes the matrix hydrocarbon oils into the retaining wall. 
Fig. 4 Single cell release model. Single cell release model of Showa by chemical reagent treatment. The hydraulic pressure caused by the dissolution of chemical reagents pushes the hydrocarbon oils into the retaining wall, which pushes the cells out of the matrix. Red and blue circles indicate hydrocarbon oils and chemical reagents, respectively

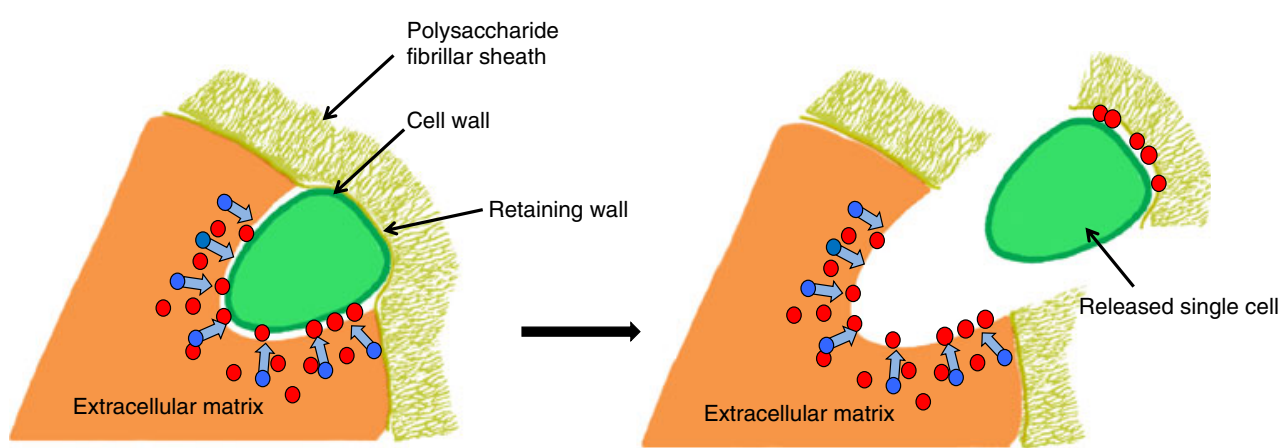

This might be the reason why the naturally accumulated shells contained no hydrocarbon oils, whereas the chemically induced shells of the B-race varieties did.

Because they were different from Showa, the cap-like structures of Yamanaka were not stained by Nile red (Online Resource 7). We speculated that in the case of Yamanaka, the retaining wall might break very easily without the need for the hydrocarbon oils being pushed into the matrix. This might be the reason why the cap-like structures of Yamanaka were not stained by Nile red. In support of this hypothesis, the appearance of the cap-like structure of Yamanaka preceded the single cell release (Online Resource 7A). Unexpectedly, we found no shell-like structures in the old culture medium of UTEX 572 (data not shown). This might simply be due to the fact that UTEX 572 lacks a retaining wall because it secretes no hydrocarbon oils. This might be the related to the finding that no chemical reagent was potent enough to release the single cells of UTEX572.

The observed phenomenon that exponentially growing colonies release significantly larger number of single cells than stationary colonies seems to be related to the release mechanism. It is possible that the retaining wall, which must be broken through cell release, is much thicker in stationary colonies than in colonies in the exponential growth phase. The thicker retaining wall may effectively reduce the number of single cells released from stationary phase colonies. This easily explains why the single cell release ratio was consistently higher in exponentially growing colonies.

\section{Putative substance essential for vital B-race single cells}

It is unclear why single cells of B-race $B$. braunii maintained at a low concentration easily lose their viability and die in a short amount of time. Additions to the medium that induce aggregation of single cells showed positive effects on the survival ratio (Table 3 ). The death of these single cells may be triggered by a decrease in the concentration of some hormone-like substance located in the oily extracellular matrix. This implies that formation of aggregates may prevent the diffusion of a hormone-like substance secreted from single cells.
A similar phenomenon has been reported in the isolated protoplasts of land plants. A high concentration is also essential for the survival of these protoplasts (Power et al. 1976). In tobacco, the protoplast concentration must be $>5 \times 10^{3}$ cells $/ \mathrm{ml}$ for survival; at lower concentrations, the protoplasts fail to divide (Evans and Cocking 1977). This implies that land plants and B. braunii B-race cells share a common mechanism or similar substance.

Considering that colonies of Showa contain typical land plant hormones (analyzed concentration of them in Showa are shown below), such as abscisic acid (1 ppm), cytokinin (1 ppm), gibberellin (5 ppm), and jasmonic acid (3 ppm) (Ohama et al. unpublished results), we attempted to culture single cells at low concentrations $\left(4 \times 10^{6}\right.$ cells $\left./ \mathrm{ml}\right)$ in medium containing these four land plant hormones at the aforementioned concentrations. However, these land plant hormones did not enhance the survival ratio of Showa single cells, nor did they induce formation of solid aggregates (data not shown). This implies the putative substance that is essential for survival of single cells may be different from these land plant hormones or another specific concentration of them is essential. Related to the above, Ikehata et al. (2011) published a brief report indicating that "conditioned culture medium," which is used culture medium prepared by removing colonies by centrifugation, enhanced the viability of single cells kept in a small vial. This also supports the existence of hormone-like substances.

Another possibility is that loss of the hydrocarbon oils surrounding the cell surface in the matrix causes cell mortality. To test this postulate, we added several drops of prepared crude Showa hydrocarbon oils to the single cells held on a membrane filters; however, this treatment had no positive effect on the survival of single cells on the membrane (data not shown). This implies that loss of the surrounding hydrocarbons is not the direct cause of cell mortality, or that the effective substance was lost during the preparation of the crude hydrocarbon oils. Therefore, the characteristics of the substance essential for the survival of Showa single cells remain unknown.

Judging from the 4',6-diamidine-2-phenylindole dihydrochloride (DAPI) stained observations, cultures of Showa and 
UTEX 572 were axenic, while those of Sanshiro-5 and Yamanaka were contaminated with bacteria. Therefore, the effects of existing bacteria on our results are unclear.

A molecular phylogenetic study of $B$. braunii showed that the three chemical races share a common ancestor (Senousy et al. 2004; Weiss et al. 2010b). Therefore, most of the observed differences in physiological characteristics among varieties must be the result of independent evolution after their divergence.

Acknowledgements This research was supported by the Core Research for Evolutionary Science and Technology (CREST) program of the Japan Science and Technology Agency.

Conflict of interest The authors declare that they have no conflict of interest.

Open Access This article is distributed under the terms of the Creative Commons Attribution License which permits any use, distribution, and reproduction in any medium, provided the original author(s) and the source are credited.

\section{References}

Banerjee A, Sharma R, Chisti Y, Banerjee UC (2002) Botryococcus braunii: a renewable source of hydrocarbons and other chemicals. Crit Rev Biotechnol 22:245-279

Blackburn KB (1936) Botryococcus and the algal coals: Part I. A reinvestigation of the alga Botryococcus braunii Kützing. Trans R Soc Edinb 58:841-853

Bold HC, Wynne MJ (1978) Introduction to the algae: structure and reproduction. In: Cultivation of algae in the laboratory. PrenticeHall INC, Englewood Cliffs, NJ, pp 571-578

Evans PK, Cocking EC (1977) Isolated plant protoplasts. In: Street HE (ed) Plant tissue and cell culture. Blackwell, Oxford, pp $103-135$

Grung M, Metzger P, Liaaen-Jensen S (1989) Primary and secondary carotenoids in two races of the green alga Botryococcus braunii. Biochem Syst Ecol 17:263-269

Ikehara F, Yamawaki Y, Matsusaki T, Kamei C, Enomoto Y, Enomoto T (2011) Development of methods for single cell separation from tight Botryococcus braunii colony. Jpn Inst Energy 216-217

Kita K, Okada S, Sekino H, Imou K, Yokoyama S, Amano T (2010) Thermal pre-treatment of wet microalgae harvest for efficient hydrocarbon recovery. Appl Energy 87:2420-2423

Komárek J, Marvan P (1992) Morphological differences in natural populations of the genus Botryococcus (Chlorophyceae). Arch Protistenk 141:65-100

Metzger P, Berkaloff C, Casadevall E, Coute A (1985a) Alkadiene-and botryococcene-producing races of wild strains of Botryococcus braunii. Phytochemistry 24:2305-2312
Metzger P, Casadevall E, Pouet MJ, Pouet Y (1985b) Structures of some botryococcenes: branched hydrocarbons from the B-race of the green alga Botryococcus braunii. Phytochemistry 24:2995-3002

Metzger P, Templier J, Largeau C, Casadevall E (1986) An $n$-alkatriene and some $n$-alkadienes from the A race of the green alga Botryococcus braunii. Phytochemistry 25:1869-1872

Metzger P, David M, Casadevall E (1987) Biosynthesis of triterpenoid hydrocarbons in the B-race of the green alga Botryococcus braunii. Sites of production and nature of the methylating agent. Phytochemistry 26:129-134

Metzger P, Casadevall E, Coute A (1988) Botryococcene distribution in strains of the green alga Botryococcus braunii. Phytochemistry 27:1383-1388

Metzger P, Casadevall E (1991) Botryococcoid ethers, ether lipids from Botryococcus braunii. Phytochemistry 30:1439-1444

Nonomura AM (1988) Botryococcus braunii var. Showa (Chlorophyceae) from Berkeley, California, United States of America. Jpn J Phycol 36:285-291

Okada S, Murakami M, Yamagichi K (1995) Hydrocarbon composition of newly isolated strains of the green microalga Botryococcus braunii. J Appl Phycol 7:555-559

Okada S, Murakami M, Yamagichi K (1997) Hydrocarbon production by the Yayoi, a new strain of the green microalga Botryococcus braunii. Appl Biochem Biotechnol 67:79-86

Okada S, Murakami M, Yamagichi K (1998) Characterization of hydrocarbons from the Yayoi strain of the green microalga Botryococcus braunii. Phytochem Anal 8:198-203

Power JB, Frearson EM, George D, Evans PK, Berry SF, Hayward C, Cocking EC (1976) The isolation, culture and regeneration of leaf protoplasts in the genus Petunia. Plant Sci Lett 7:51-55

Sawayama S, Inoue S, Dote Y, Yokoyama SY (1995) Carbon dioxide fixation and oil production through microalga. Energ Convers Manage 36:729-731

Senousy HH, Beakes GW, Hack E (2004) Phylogenetic placement of Botryococcus braunii (Trebouxiophyceae) and Botryococcus sudeticus isolate UTEX 2629 (Chlorophyceae). J Phycol 40:412-423

Templier J, Largeau C, Casadevall E (1984) Mechanism of nonisoprenoid hydrocarbon biosynthesis in Botryococcus braunii. Phytochemistry 23:1017-1028

Templier J, Largeau C, Casadevall E (1991) Biosynthesis of $n$-alkatrienes in Botryococcus braunii. Phytochemistry 30:2209-2215

Tonegawa I, Okada S, Murakami M, Yamaguchi K (1998) Pigment composition of the green microalga Botryococcus braunii Kawaguchi-1. Fish Sci 64:305-308

Weiss TL, Chun HJ, Okada S, Vitha S, Holzenburg A, Laane J, Devarenne TP (2010a) Raman Spectroscopy analysis of botryococcene hydrocarbons from the green microalga Botryococcus braunii. J Biol Chem 285:32458-32466

Weiss TL, Johnston JS, Fujisawa K, Sumimoto K, Okada S, Chappell J, Devarenne TP (2010b) Phylogenetic placement, genome size, and $\mathrm{GC}$ content of the liquid-hydrocarbon-producing green microalga Botryococcus Braunii strain Berkeley (Showa) (Chlorophyta). J Phycol 46:534-540

Weiss TL, Roth R, Goodson C, Vitha S, Black I, Azadi P, Rusch J, Holzenburg A, Devarenne TP, Goodenough U (2012) Colony organization in the green alga Botryococcus braunii (Race B) is specified by a complex extracellular matrix. Eukaryot Cell 11:1424-1440 